

\title{
APARIENCIAS DE LA VARIACIÓN: FISONOMÍA Y ALEGORÍA EN EL RETRATO CINEMATOGRÁFICO DE INGMAR BERGMAN
}

\section{APPEARANCES OF VARIATION: PHYSIOGNOMY AND ALLEGORY IN THE FILM PORTRAIT BY INGMAR BERGMAN}

\author{
David Vázquez Couto \\ Universidad de Salamanca, España \\ davidcouto@usal.es
}

\section{Resumen:}

El retrato cinematográfico es una cuestión fundamental y connatural al propio medio si se considera bajo la óptica conceptual del autor sueco Ingmar Bergman. La filmación de la expresión de las facciones en su continuidad móvil y variable, fugaz ante los imperativos temporales que impiden su aprehensión si no es mediante la materialidad de la imagen, resulta ser el pábulo elemental de su prolífica obra cinematográfica. En este sentido, el rostro opera como una apertura al sujeto interpretado y creado alegóricamente por el otro, por el observador que reconoce las pasiones fluctuantes y manifiestas en la fisonomía del modelo con la intención de alcanzar su inteligibilidad. Así pues, Bergman emprende la búsqueda del individuo en la inestabilidad morfológica del rostro utilizando la técnica cinematográfica, especialmente a través del recurso del primer plano, único capaz de ofrecer la ilusión de su cristalización temporal sobre el celuloide.

\begin{abstract}
:
The cinematographic portrait is a fundamental and inherent subject to the medium itself if considered under the conceptual perspective of swedish author Ingmar Bergman. The shooting of the expression of the features on its mobile and variable continuity, fleeting against the time constraints that impede its apprehension if not by the materiality of the image, turns out to be the elemental pabulum of his prolific film work. In this sense, the face operates as an opening to the subject created and allegorically interpreted by the other, by the observer that recognizes the fluctuating and manifest passions in the physiognomy of the model with the intention of achieving its intelligibility. Therefore, Bergman undertakes the search of the individual in the morphological instability of the face using the film technique, especially through the close-up resource, the only able to provide the illusion of its temporary crystallization on celluloid.
\end{abstract}

\section{Palabras clave:}

Ingmar Bergman; cine; rostro; fisonomía; retrato; primer plano.

Keywords:

Ingmar Bergman; Cinema; Face; Physiognomy; Portrait; Close-up. 


\section{Hacia el retrato cinematográfico de Ingmar Bergman}

\subsection{Introducción}

Eternizar el momento huidizo del presente en la materialidad y duración del film es una condición sine qua non al cine, sin embargo, intentar consumar el acto comunicativo revelando la verdad oculta en el otro a través del rostro reteniendo con la cámara su apariencia fluctuante- es una condición esencial en la obra de Ingmar Bergman. En una pieza fílmica familiar y anecdótica curiosidad documental de $16 \mathrm{~mm}$ incluida en el largometraje colectivo Stimulantia (1967)-, el cineasta expone sus obsesiones sobre el rostro de su hijo Daniel con estas palabras finales: "Para llegar a una persona, en lugar de envolverla, hay que experimentar con ella sus miles y miles de variaciones. Vivir juntos en una realidad común" (9’34”). El texto poético se complementa con el lenguaje cinematográfico para dar lugar a un legado íntimo del autor que problematiza sobre la finalidad del cine como herramienta capaz de analizar y diseccionar la multiplicidad expresiva del rostro. Bergman afirma -y lo demuestra con su obra- que el rostro debe ser el objetivo principal del cine: "Nuestro trabajo en el cine debe comenzar con el rostro humano. [...] el enfoque de la cara es sin duda el sello y la característica distintiva del medio cinematográfico" (Alpert, 1961, p. 40).

Pues bien, partiendo de esta premisa, trataremos de recorrer el mismo camino que una vez llevó a Ingmar Bergman hasta las profundidades del rostro mediante la fisiognomía. Y es que el estudio del carácter del hombre desde su fisonomía, es decir, desde el aspecto sensible del rostro según sus facciones, permite especular sobre la captación de la supuesta verdad oculta en el rostro mediante el registro mecánico de la realidad. Bergman se sirve de la imagen cinematográfica para reflexionar sobre la imagen del hombre, para intentar ir más allá de su superficie material en busca de lo inmaterial: “de repente tenía la posibilidad de relacionarme con el mundo en un idioma que literalmente habla de alma a alma en giros que, de una manera casi voluptuosa, se sustraen al control del intelecto" (Bergman, 1992, p. 47). La consumación del acto comunicativo, por tanto, parece posible mediante la 
imagen en movimiento que sólo es capaz de ofrecer el cine. Aquello que Proust definía como ese "algo en nosotros que se esfuerza en reducir esos sentimientos particulares a una mayor verdad; es decir, a hacer que se adhieran a un sentimiento más general, común a toda la humanidad” (2007, p. 148), se convierte en el sueño bergmaniano y en la obsesiva finalidad de su cine. La superficie de la pantalla es, como un rostro que nos mira, una ventana cerrada al interior del hombre que Bergman intenta abrir una y otra vez con voluntad de encontrar "la chispa íntima de la vida” (Bergman, Burke, Swahn \& Munk, 1966, p. 99). Así, por ejemplo, durante la obertura de La flauta mágica (Trollflöjten, 1975), Bergman no muestra la acción de la ópera de Mozart sobre el escenario, sino el rostro contemplativo de los espectadores que, fragmentados e individualizados mediante primeros planos montados acorde al ritmo de la música, sugieren la idea de que "el rostro es el espejo no ya del universo que le rodea, sino de la acción que se desarrolla off, es decir, fuera del campo" (Morin, 2001, p. 68). La intención no es otra que desvelar los estados del alma ante la recepción de estímulos externos, al igual que la intención del príncipe Hamlet es dilucidar el gesto de la traición en el rostro del rey Claudio mientras asiste a la puesta en escena de una pequeña obra teatral titulada La ratonera ${ }^{1}$.

El primer plano del rostro alcanza con Bergman la categoría de retrato, tal y como es definido por Aumont: "el acto más importante que se pueda concebir respecto al rostro, ya que implica la unidad de ese rostro en su verdad, o al menos con vistas a su verdad, debiendo ser esa unidad contradictoria y tener en cuenta las laminaciones del rostro” (1998, p. 27). A esta concepción del retrato que conserva un tinte barroco se suma la capacidad específica del cine que posibilita la "huella de la duración" (Bazin,

${ }^{1}$ Durante el tercer acto de la obra de Shakespeare -recuérdese que la división editorial en actos es posterior a las costumbres del teatro isabelino-, el príncipe Hamlet conjura contra su tío, el Rey Claudio, con la ayuda de Horacio: "Esta noche se representa un drama delante del rey: una de sus escenas contiene circunstancias muy parecidas a las de la muerte de mi padre, de que ya te hablé. Te encargo que cuando este paso se represente, observes a mi tío con la más viva atención del alma: si al ver uno de aquellos lances su oculto delito no se descubre por sí solo, sin duda el que hemos visto es un espíritu infernal, y son todas mis ideas más negras que los yunques de Vulcano. Examínale cuidadosamente: yo también fijaré mi vista en su rostro, y después uniremos nuestras observaciones, para juzgar lo que su exterior nos anuncie" (1825, p. 114). 
1990, p. 173). Es entonces cuando se puede hablar de retrato cinematográfico, puesto que el fragmento aislado de la acción o el simple encuadre del rostro no supone más que una visión formalista del género. Así pues, el retrato ha de intentar desvelar aquello que la fisonomía esconde, salvando al ser del tiempo con la ilusión de convertirlo en espacio a través su imagen. Bergman filma, descompone, observa, analiza la inmensidad gestual del rostro en todas sus variaciones surgidas de las emociones para llegar a conocer su lado en sombras.

\subsection{Metodología}

Ingmar Bergman declaró en varias ocasiones que siempre fue un ávido lector, y aunque son de sobra conocidos los autores de las obras dramáticas que ha llevado a escena como director de teatro (Shakespeare, Moliere, Strindberg o Ibsen, entre muchos otros), nunca ha reconocido sus influencias en el ámbito de la teoría del conocimiento -ya sean problemas existenciales del hombre o cuestiones referentes a los medios de representación audiovisual-. En una entrevista publicada en 1989 Bergman explica que el autor debe tener completamente claro su ideario artístico y filosófico, aunque también advierte de la inconveniencia de ofrecer al público el significado de la obra, ya que puede llegar a entorpecer la sugestión, la emoción y la alegría del espectador durante la experiencia receptiva de la película (Livingston, 2009, p. 128). No obstante, esta afirmación se limita al fenómeno contemplativo de la obra, es decir, a la ensoñación y fascinación en la que se sumerge el espectador en la sala de cine. Por este motivo entendemos que, cuando las intenciones de un autor están suficientemente integradas con las características relevantes del texto o la imagen -en este caso, la materialización fílmica de un postulado filosófico-, el conocimiento de sus fuentes creadoras ayudan a determinar el contenido de la obra. Esto denota la importancia de una estructura formal que configura y presenta el concepto -la forma satisface al contenido de sus pensamientos-, siendo oportuno realizar una aproximación a la técnica que forja su estilo único y personal, 
obstinado en mostrar la dicotomía entre el carácter interno y externo del individuo desde un estudio fisonómico que se traduce, a su vez, en una preocupación por lo visible y lo invisible, por la condición (de)mostrable de la realidad. En consecuencia, trataremos de contribuir a un mejor conocimiento de la obra de Ingmar Bergman desde una perspectiva teórico-crítica de carácter interpretativo, ofreciendo las claves teóricas que fundamentan su praxis artística en relación al retrato cinematográfico mediante el análisis de una pequeña muestra de su filmografía. En definitiva, la principal inquietud será la demostración de su utilización del primer plano del rostro como técnica capaz de superar la superficialidad de la forma, llegando a ser una vía de comunicación y conocimiento del hombre.

\section{Alegorías del rostro}

\subsection{La actividad creativa del espectador}

Bergman cuenta que, cuando falleció su madre, él heredó las fotografías familiares. Al describir la experiencia de revisarlas escribió: "Me meto en las imágenes y toco a las personas, a las que recuerdo y aquellas de las que no sé nada. [...] Yo me invento mis propias pautas" (1998, p. 9). Es posible, por tanto, aventurar una interpretación sobre la idea de que el carácter arcano de la fotografía produce un efecto de exaltación imaginativa en el observador, quien, a través de la imagen, extrae de la memoria una ausencia revivida en su consciencia. Este proceso, que hace realidad la "presencia de la ausencia" a la que se refería Morin (2001, p. 26), actualiza un tiempo pasado mediante un estado interpretado y conjeturado por el receptor que se remonta al translatio ad prototypum²; doctrina que, tempranamente, parece poner de

\footnotetext{
2 Doctrina surgida en el año 787 durante el II Concilio de Nicea que "tiene una matriz platónica, pues la imagen es concebida como mero reflejo de una realidad sobrenatural y suprasensible, pero también encontró apoyo en la teoría de aristotélica del signo, pues la distinción entre simulacro icónico (la imagen) y el prototipo (el sujeto representado) era congruente con la distinción aristotélica entre la materialidad del signo (lo que hoy llamamos significante) y aquello que designa (su referente). La doctrina de la translatio ad prototypum aclaraba, además, la distinción entre la adoración de la imagen (propia de la idolatría) y la adoración ante la imagen (del ser representado en ella)" (Gubern, 2004, p. 88).
} 
manifiesto algunas de las cuestiones acerca de la imagen que serán abordadas durante la modernidad con motivo de la aparición de los nuevos dispositivos mecánicos de representación. Con la reproducción técnica la ficción surge a partir de la huella que ha dejado la realidad en el soporte fotosensible -de la misma manera que las arrugas y las cicatrices son improntas que deja el tiempo sobre la piel- para sobrevenir en una contemplación melancólica, puesto que la fotografía “condensa la pulsión fetichista de la suturación de la pérdida, el intento por aliviar el deseo insatisfecho de la aprehensión" (Del Río, 2008, p. 65). El observador melancólico, por lo tanto, sigue el rastro de lo que ya no existe, imagina el reencuentro con un pasado irrecuperable con la intención de crear un nuevo presente que da como resultado, en palabras de Bazin, una "alucinación verdadera” (1990, p. 30). Se trata, al fin y al cabo, de un procedimiento alegórico asentado en el principio de insuficiencia de la representación, es decir, de una creencia de que la representación no es válida por sí misma y necesita el acto creativo del receptor para completar su significado. Las teorías de la acción comunicativa llamarían competencia cognoscitivavalorativa del oyente a lo que en las artes plásticas es "el acto creativo", propuesto en 1957 por Marcel Duchamp durante una intervención en la American Federation of Arts en Houston: "Con todo, el acto creativo no se lleva a cabo sólo por el artista; el espectador aporta el trabajo en contacto con el mundo exterior descifrando e interpretando sus calificaciones internas, y así añade su contribución al acto creativo” (1975, p. 140). De manera que, ante la "condena a la significancia abierta" que supone el uso del lenguaje alegórico (Brea, 1991, p. 17), la idea de Duchamp apuesta por la imposibilidad de la comunicación sin la participación del receptor. No obstante, José Luis Brea matiza que la alegoría duchampiana inaugura una "estética de la recepción” (1991, p. 21), pero no como lo había expuesto Heidegger en El origen de la obra de arte (1950), es decir, como forma general de lo artístico, sino con “el bagaje 'selvático' que arrastra de su origen barroco” (1991, p. 29), tal y como Walter Benjamin advierte al vincular la alegoría con la melancolía en la figura de Baudelaire. En este sentido, Benjamin teoriza también sobre 
Marcel Proust, autor que propone claves pertinentes en relación a la construcción alegórica del otro mediante el refuerzo de la memoria y la imaginación. Su narrador de El mundo de Guermantes explica el estado de enamoramiento de su amigo Saint-Loup, quien se obsesiona por Raquel, una mujer que lleva una doble vida a espaldas de su amante.

Me hacía yo cargo de todo lo que una imaginación humana puede poner tras un pedacito de cara como era la de aquella mujer, con tal de que sea la imaginación la que primero la ha conocido, e inversamente en qué míseros elementos materiales y desprovistos de todo valor, inestimables, podía descomponerse lo que era el fin de tantos ensueños si, por el contrario, hubiera sido conocido eso mismo de una manera opuesta, con el conocimiento más trivial (2007, p. 196).

Este despertar del espectador supone una percepción sobre el modelo que permite superar las limitaciones impuestas por el material a partir de los rasgos inefables del rostro. Es lo que Gombrich denomina la contrapartida del observador, proceso por el cual "tendemos a proyectar vida y expresión en la imagen estática y a añadir, a partir de nuestra experiencia, lo que falta en realidad”. Gombrich prosigue con la descripción y determina que, para que sea posible la proyección creativa sobre el modelo, el autor debe tener la capacidad de "explotar las ambigüedades del rostro estático de forma que la multiplicidad de las posibles lecturas produzca un aspecto de vida. El rostro inmóvil debe parecer un punto nodular de los muchos movimientos expresivos posibles" (1996, p. 34). El semblante, pues, como dimensión especular del tiempo, prontuario de las múltiples oscilaciones prácticamente imperceptibles que se evaporan ante nuestros ojos.

Siguiendo las ideas de José Luis Brea acerca de que en la actualidad se está produciendo un efecto barroco en la representación construida mediante nuevas estrategias alegóricas, hallamos en la escenificación "aquella curvatura del espacio característica del barroco que hacía ingresar, como dimensión añadida, su decurso en el tiempo" (1991, p. 39). Por consiguiente, el desplegar temporal que relumbra en la consciencia del espectador aviva su capacidad de reconocimiento y alusión de algo inaprensible cuya 
indefinición, oculta tras las facciones, crea el mito de su propia existencia. Bergman toma las riendas del retrato cinematográfico consciente del espacio para lo alegórico alojado en el rostro que, abnegado a permitir la intervención del flujo del tiempo sobre sí, aparece en el material fílmico como una manifestación de la variación.

\subsection{Aparición estática de las variaciones del rostro}

Bergman realiza un montaje fílmico con las fotografías de su madre al que titula El rostro de Karin (Karins ansikte, 1984). Desde la primera imagen de los tres años hasta la última, tomada unos meses antes de morir, Bergman superpone, funde, encadena, diluye el rostro de su madre capturado en distintos momentos de su vida para mostrar los cambios de personalidad vinculados a su fisonomía (F1). De esta manera el director encuentra en el cine la posibilidad de aprehender aquellos rostros de las fotografías antiguas, difusos, casi espectrales, en los que se registraban multitud de pequeños gestos y expresiones debido a las largas exposiciones a la luz necesarias para eternizar la escena sobre el material fotosensible. Los ligeros movimientos del modelo producidos durante el tiempo de espera provocan la aparición de la variación en el instante. Bertolt Brecht reflexiona en Tentativas (1931) sobre este curioso efecto, específico por aquel entonces del daguerrotipo, que resulta especialmente ventajoso para el retrato, puesto que "múltiples expresiones aparecían en la placa, [...] de modo que en la imagen final se lograba una expresión más universal y viva” (Benjamin, 2007, p. 120). En el material, por tanto, se sintetiza lo inabarcable de la multiplicidad plástica que define el rostro en movimiento. En Pequeña historia de la fotografía Walter Benjamin afirma que "el procedimiento mismo inducía a los modelos a vivir, no fuera, sino dentro del instante. Durante la larga duración de estas tomas crecían, por así decirlo, dentro de la imagen, contrastando de este modo decisivamente con los aspectos de la instantánea” (2007, p. 31). Se produce así una espacialización del tiempo, una condensación material de la duración de la exposición que parece atrapar el espectro del devenir. 




F1. El rostro de Karin (Karins ansikte, 1984)

En este punto parece inevitable recordar que Roland Barthes escribe $L a$ cámara lúcida poco después de la muerte de su madre. Esta obra se convierte en una búsqueda romántica de la esencia de la fotografía que encuentra su sentido en la muerte. Al igual que Bergman, Barthes trata de encontrar entre todas las fotografías de su madre alguna que recupere la unicidad de su ser en la expresión de su rostro congelado en el tiempo. Al fin descubre una fotografía de cuando ella tenía cinco años y parecía conservar toda su pureza e inocencia. Su hijo la ve retenida en la imagen, reconociéndola tal y como la recuerda. Es la Fotografía del Invernadero la que certifica utópicamente "la esencia imposible del ser único" (Barthes, 1989, p. 113), ofreciendo así la verdad y no sólo la identidad de su madre. En su epílogo teórico Barthes reconoce los límites de la semiótica como disciplina capaz de descifrar lo que ocultan algunas imágenes, decantándose, finalmente, por una mirada idealista que abre las puertas de la extraña combinación de luces y sombras que dan forma estática al mundo representado a través del rostro. El amor filial construye un relato ficcional sobre la imagen materna, tal y como describe el narrador de Proust al contemplar furtivamente la figura de su abuela en El mundo de Guermantes: 
Nunca vemos a los seres queridos como no sea en el sistema animado, en el movimiento perpetuo de nuestro incesante ternura, que, antes de dejar que las imágenes que su rostro nos presenta lleguen hasta nosotros, arrebata en su torbellino a esos seres, los lanza sobre la idea de que ellos nos formamos desde siempre, hace que se adhieran a ella, que coincidan con ella (2007, p. 173).

Como ya había señalado Kracauer al retomar este pasaje para explicar su concepción del fotógrafo, Proust incide en la idea de que el amor empaña la mirada que el observador vierte sobre la persona amada, impidiendo así ver la realidad de su transformación ocasionada por el tiempo (1996, p. 35). El amor, o la idea preconcebida que se tiene del otro, deviene en que "cada mirada casual es un acto de nigromancia, cada rostro que amamos un espejo del pasado" (Proust, 2007, p. 173). Hasta llegar a esta conclusión, el narrador de Proust reconoce que todo lo que sabía de su abuela, o más bien, todo lo que creía saber, lo encontraba en "la partitura abierta de su rostro" (2007, p. 166). En este sentido es recurrente la idea expuesta por Béla Balázs en su Das unsichtbare Antlitz de 1926: "la mímica del rostro tiene también la posibilidad de expresar lo no-mostrado, e, igualmente, de manifestar, entre sus rasgos, lo invisible” (Aumont, 1998, p. 90). En consecuencia, Balázs cree que el rostro en sí mismo contiene una verdad encriptada en la configuración de sus facciones, pues tras las expresiones faciales se esconden múltiples sentimientos y emociones que actúan simultáneamente en lo que él llama polifonía del rostro. Algo parecido ya había pensado el pintor Charles Le Brun en sus Conférences sur l'expression des passions de 1668; estudio morfológico de la expresión facial que establece una teoría en la que los signos externos del rostro reproducen los estados emocionales del hombre (Gubern, 2004, p. 97). Con la misma intención, aunque utilizando un procedimiento distinto, Bergman trata de ordenar mediante el montaje la diversidad expresiva contenida en los ojos y en los labios, en los gestos y en las arrugas que narran la historia de su madre desde la infancia hasta la vejez, cuando finalmente "parece como si un viento helado hubiera soplado sobre su rostro, las facciones se han desplazado un poco" (Bergman, 1988, p. 306). En estos últimos años de la vida de Karin, Bergman parece observar a 
su madre desde la distancia que impide su reconocimiento. De la misma manera, el narrador de Proust descubre una áspera realidad durante el encuentro con su abuela:

Y así como un enfermo que desde hace tiempo no se había visto a sí mismo y venía componiendo a cada momento el semblante que no ve, ajustándolo a la imagen ideal que de sí mismo lleva en su pensamiento, retrocede al percibir en un espejo, en medio de un rostro árido y desierto, la prominencia oblicua y sonrosada de una nariz gigantesca como una pirámide de Egipto, así yo, para quien mi abuela era todavía yo mismo, yo, que jamás la había visto fuera de mi alma, siempre en el mismo lugar del pasado, a través de la transparencia de los recuerdos contiguos superpuestos, de repente, en nuestro salón, que formaba parte de un mundo nuevo, el del tiempo, el mundo en que viven los extraños de quienes se dice "lleva bien su vejez", por vez primera y sólo por instante, porque desapareció bien pronto, distinguí en el canapé, bajo la lámpara, colorada, pesada y vulgar, enferma, soñando, paseando por un libro unos ojos un poco extraviados, a una vieja consumida, desconocida para mí (2007, p. 174).

Se produce así un fenómeno de extrañamiento efímero durante la contemplación que posibilita el acercamiento a la realidad escondida. Un “estado de enajenación”, utilizando la definición de Kracauer, cuya mirada libre de todo anclaje sentimental o emocional favorece la identificación con el objeto mediante una actitud melancólica (1996, pp. 37-38). Materializar este preciso momento, propicio para el correcto registro de las cualidades físicas del rostro que actúan como reflejo exaltado de las emociones y de la experiencia, es el objetivo principal del cine de Ingmar Bergman, ya que "estamos ante una máquina abstracta de agenciamientos que territorializa, según la ley despótica del significante, la vida psíquica en su totalidad” (Brea, 1991, p. 109). En cualquier caso, el desgaste que el peso de la vida ocasiona sobre el rostro se muestra con franca crudeza en este último homenaje que Bergman brinda a su madre.

Al margen de esta pieza dedicada con afecto de vástago, en la filmografía bergmaniana se hallan muestras de sus inquietudes fisiognómicas desde un punto de vista en el cual "la cámara debe ser un observador completamente 
objetivo" (Bergman, et al, 1966, p. 99). Éste es el método de Elis Vergérus (Erland Josephson), el fotógrafo obsesionado con el estudio del rostro en Pasión (En passion, 1969), que acumula cientos y cientos de retratos clasificados en un gran archivo con la intención de investigar las conductas del modelo a partir de los rasgos faciales. Como un científico que observa el mundo a través del microscopio, Elis explora compulsivamente las facciones del rostro mediante la fotografía, aunque reconoce que su labor es inútil cuando dice: "Creo que no puedo llegar al alma con mis fotografías. Sólo registro una interacción de fuerzas grandes y pequeñas. Luego miro la foto y dejo volar mi imaginación. Es una tontería, juegos, poemas. No puedes entender con certeza a la otra persona” (53'50”). El ideal romántico canalizador de sus esfuerzos en torno al sujeto deja paso a una resignada mirada materialista cercana a la expuesta por Hume, quien considera el yo como algo intangible e imperceptible en sí mismo, y que, en consecuencia, resulta imposible hallar las pruebas de su existencia. Tan sólo es posible experimentar la percepción de ciertas cualidades o de estados reflejados exteriormente, puesto que los "seres humanos no son sino un haz o colección de percepciones diferentes, que se suceden entre sí con rapidez inconcebible y están en perpetuo flujo y movimiento" (Hume, 1988, p. 356). A fin de cuentas, se trata de una cuestión de fe, de creencia sobre lo indemostrable, porque si esa verdad está ahí, oculta en el rostro, sólo es alcanzable en la imaginación subjetiva del observador. El yo, entonces, no es más que una construcción alegórica que esquiva la realidad de la nada en la mente de su espectador, pues el enunciado del sentido en el rostro se plantea a la deriva de una inconclusión temporal.

\section{Retratos sin rostros}

\subsection{Vacuidad tras la máscara}

Si ya Brecht afirmaba en 1931 que "los nuevos aparatos fotográficos ya no componen los rostros", puesto que fijan con nitidez el instante fugaz de la toma, también se cuestiona si en verdad es necesaria su composición e intuye 
que es posible "un nuevo modo de fotografiar, accesible a los nuevos aparatos, que descompone los rostros" (Benjamin, 2007, p. 120). El dramaturgo alemán parece anticiparse con estas palabras a los principios que ocuparán la cinematografía del director sueco a partir de los años cincuenta, llegando al apogeo de su complejidad con los retratos nihilistas realizados durante las décadas de los sesenta y setenta. El verdadero rostro, si es que hay tal rostro, se oculta una y otra vez bajo una infinitud de láminas. Capa sobre capa, máscara sobre máscara, parece imposible llegar al fondo del precipicio. En El Rostro (Ansiktet, 1958), Bergman ilustra lúcidamente el conflicto entre el idealismo, que promete la existencia de algo más allá de lo visible, y el racionalismo, que lo desmiente como patraña quimérica. Max von Sydow, irreconocible al caracterizarse como una especie de figura de cera, interpreta al mago e hipnotizador Vogler. A mediados del siglo XIX Vogler llega a Estocolmo para realizar un espectáculo ilusionista, sin embargo, el misterioso disfraz y sus fantásticas habilidades despiertan la curiosidad del comité científico encabezado por el escéptico doctor Vergérus (Gunnar Björnstrand), quien trata de comprender el cuerpo como objeto, como soporte material que configura la imagen del hombre. El mago se ve sometido a un agresivo análisis fisiológico que pretende desmentir la ilusión inexplicable que tiene lugar ante sus ojos, pero personaje y persona, realidad e fantasía se confunden en la figura del protagonista, que no es más que su propia ficción. Otro personaje, un actor mediocre llamado Johan Spegel muere ante la atenta mirada de Vogler, quien ansía descubrir en sus ojos el secreto que pertenece a la muerte, aunque su búsqueda no encuentra una completa satisfacción al "deseo constante de experimentar reacciones y tensiones en la mirada” (Bergman, et al, 1966, p. 99). Más adelante, Spegel se aparece ante el protagonista como un fantasma, y jugando con la imagen de una linterna mágica dice: "Soy una sombra de una sombra. [...] Uno va avanzando paso a paso hacia la oscuridad pero el movimiento es la única verdad" (55'30") (F2). Realizando una analogía entre hombre e imagen cinematográfica, Bergman muestra su convicción sobre la imposibilidad 
cognoscible de la identidad en el transcurso del tiempo, pues ésta se adhiere a una superficie inestable y cambiante, en continua fuga de la aprehensión.



F2. El Rostro (Ansiktet, 1958)

La inexorable decadencia del cuerpo que se revela en el movimiento y la transición parece ser el único síntoma demostrable de la realidad. En el rostro "habita el sujeto", y es entonces cuando el impulso de buscar el alma dentro de un cuerpo frágil y corrupto -prisión carnal que impide liberarse a la substancia eterna y pura-, se lleva a cabo a través de esta "superficie liminar de tránsitos tejida de orificios, de ausencias, de oquedades: boca, nariz, orejas, ojos. Ninguno de ellos es por sí mismo, sino puro enclave de un tránsito" (Brea, 1991, p. 107). El cuerpo, por tanto, es un reloj de arena que advierte de la brevedad de la existencia heredera de aquel tempus fugit de Virgilio. Ahora bien, en "la necesidad de aventajar la naturaleza", como escribe Baudelaire en El pintor de la vida moderna (1863/1995, p. 102), el hombre busca detener el tiempo que afecta a su propia materia física. El maquillaje juega aquí un papel significativo como elemento que oculta o distorsiona las cualidades del verdadero rostro, y como la máscara, 
proporciona una ficción inmutable a su portador. Sin embargo, este artificio encubridor de la carne desgastada -recuerdo de un tiempo ya perdido e irrecuperable- no sólo muestra el deseo de una identidad sostenida sobre la ausencia, sino que pretende la misma ilusión de retención temporal sobre el cuerpo que la técnica fotográfica ofrece sobre el material cubierto de bromuro de plata. Y si Bazin advertía que la fotografía "embalsama el tiempo; se limita a sustraerlo a su propia corrupción” (1990, p. 29), el maquillaje trata de hacer algo semejante con el rostro de aquel que anhela una estética de lo estático en el fluir del tiempo existencial. En cualquier caso, la ocultación de las emociones tras el espesor del afeite es uno de los principales escollos a superar si se pretende completar el acto comunicativo; y por este motivo, Bergman prohibía la utilización del maquillaje a sus actores y actrices -salvo por justificación argumental-, pues sólo así se puede evitar el entorpecimiento visual del verdadero rostro. Así lo confirma Liv Ullmann en una entrevista concedida en 1980:

Nunca debo usar maquillaje, ni en sus películas ni en sus obras de teatro. Hay muchos beneficios en el poder mostrar lo que no se puede expresar con el maquillaje. [...] Tu cara puede ponerse pálida o colorada cuando sufres las emociones, en el escenario y en la vida (Wexman \& Ullmann, 1980, p. 77).

Cerca del delirio onírico final de La hora del lobo (Vargtimmen, 1968), una decrépita mujer se deshace de su cara cubierta de un espeso maquillaje que oculta el vacío que hay debajo (67'30") (F3). Algo similar ocurre en otro sueño, esta vez en Cara a cara (Ansikte mot ansikte, 1976), donde una psicóloga - "analfabeta del alma humana" (Bergman, 1997, p. 15)- encuentra llagas y heridas sangrantes tras la piel desprendida de la cara de una de sus pacientes (72'05") (F4). Se trata de un rostro necrótico consumido y descompuesto en la sombra interior que produce el rostro externo, un constructo artificial erigido sobre la ausencia. Es por ello que Bergman encuentra en el rostro la tragedia de la máscara, que no es otra cosa que la imposibilidad de alcanzarse a sí mismo y a los demás debido a la pérdida de la esencia en el laberinto de la apariencia. Aumont, recuperando un término que aparece en Los cuadernos de Malte Laurids Brigge de Rilke, denomina 
no-rostro a esta ruina que se esconde y se pudre bajo la apariencia, y que será el principio del fin para el rostro (1998, p. 165).
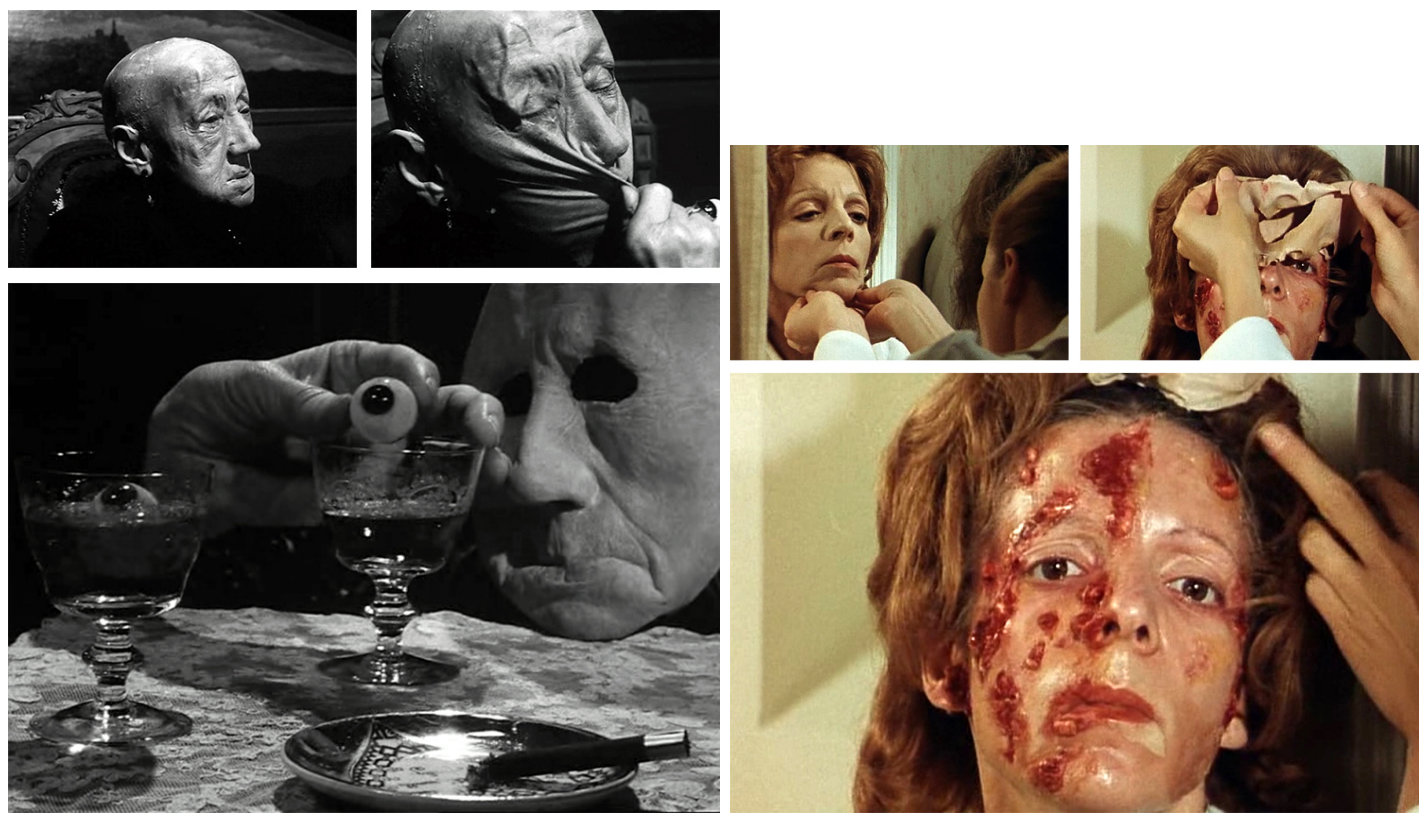

F3 La hora del lobo (Vargtimmen, 1968)

F4 Cara a cara (Ansikte mot ansikte, 1976)

Hay mucha gente, pero más rostros aún, pues cada uno tiene varios. Hay gentes que llevan un rostro durante años. Naturalmente, se aja, se ensucia, brilla, se arruga, se ensancha como los guantes que han sido llevados de viaje [...]. Otras gentes cambian de rostro con una inquietante rapidez. Se prueban uno después de otro, y los gastan. Les parece que deben de tener para siempre, pero apenas son cuarentonas y ya es el último. Este descubrimiento lleva consigo, naturalmente, su tragedia. No están habituados a economizar los rostros; el último está gastado después de ocho días, agujereado en algunos sitios, delgado como el papel, y después, poco a poco, aparece el forro, el no-rostro, y salen con él. [...] La mujer no asustó, se arrancó de sí misma. Demasiado deprisa, demasiado violentamente, de manera que su cara quedó en sus dos manos. Pude verlo, y ver su forma vaciada. Me costó un esfuerzo indescriptible quedarme en esas manos, no mirar hacia aquello de que se había despojado. Me estremecí al ver un rostro tan dentro, pero daba más miedo la cabeza desnuda, desollada, sin rostro (Rilke, 1958, pp. 2122). 
Ingmar Bergman lanza una mirada descreída hacia el interior del ser humano que se pierde en el vacío, pues en su tenaz intento de despojar al rostro de las capas que encubren la verdad, no encuentra otra cosa que la sospecha de la nada al fondo de un profundo abismo. En Demonerna, el quinto acto de su epílogo cinematográfico Fanny y Alexander (Fanny och Alexander, 1982), Edvard Vergérus (Jan Malmsjö) le confiesa a su mujer: "Yo sólo tengo una máscara, pero está pegada a mi piel. Si tratara de quitármela..." (41'32”). El estricto pastor luterano sospecha que es falsa la promesa de una existencia más allá de la máscara, pues se parece advertir que la única verdad no puede ser otra que la de su propia impostura. Y es que sobre el hombre retratado por Bergman aparece la sombra de Nietzsche: "Quien tratase de tocar tales máscaras creyéndolas auténticas antes que un mero juego de marionetas -es que todos ellos fingen ser auténticos- de inmediato encontraría en sus manos nada más que harapos y parches coloridos" (2006, p. 67). El proceso de descomposición del rostro en la obra de Bergman implica, no obstante, que esa causa interior tiene su inmediato efecto externo delimitado en las facciones, por lo que se parte de la presunción conceptual de la existencia de un origen y una réplica, de una pasión y un gesto coincidentes en la superficie del rostro, para llegar a la desoladora conclusión de que esencia y apariencia se diluyen en un mismo espacio vacío.

\subsection{Primer plano del rostro}

Para llegar a estos resultados Bergman incluye en su método de estudio el lenguaje cinematográfico como instrumento de disección corporal en imágenes. El control técnico de la ilusión resulta indispensable para decir lo indecible y potenciar las cualidades de la realidad. Así, dominar la luz, como una mentira creíble, es un arte que consiste en dar una apariencia de realidad a la escena sin que se note la manipulación, como reconoce el cineasta al afirmar que "en lo que se refiere a la luz, una mentira ha sucedido a otra" (1973, p. 175). La luz es un elemento aliado que se disuelve en la escena entre 
los gestos de los actores, pero Bergman no sólo considera la luz como expresión en sí misma, sino que le resulta indispensable para mediar en la expresión del actor con la finalidad de extraer las cualidades de su rostro. Luz y rostro se fusionan para dar una forma a la creación como lo haría un pintor del barroco, tratando de revelar una apariencia intangible en la mirada del retratado que se recibe como una esencia sin forma. Parece que hay cualidades más allá de la superficie material que ofrece la realidad, pues logra esa imprecisión identificativa en el rostro que adquiere un carácter de infinitud y estimula la imaginación del espectador. Sven Nykvist, director de fotografía y colaborador habitual de Bergman desde Noche de circo (Gycklarnas afton, 1953), modela con la luz para tratar cada mínimo detalle del entorno con delicadeza, observando cómo las luces y las sombras dan vida a la materia mientras procura retener ese instante mágico con la cámara. La calidez lumínica envuelve la acción para favorecer al rostro; lo intensifica, lo acompaña y lo concentra sin exagerarlo, ya que una luz dura y contrastada haría desaparecer las modulaciones de sus matices. Nykvist afirma que trata de ser "una especie de intermediario sensible entre el actor y el objetivo", y reconoce, además, la influencia de Bergman, quien le ayudó entender la iluminación como una forma de acercarse al alma mediante el descubrimiento del rostro: "Fue también Ingmar quien despertó en mí el interés por los rostros, y sus constantes cambios en los rasgos y en las miradas. La verdad suele anidar en los ojos del actor. Si se muestran los ojos, desnudan su alma” (1998, pp. 236-237).

Bergman insiste en la ordenación de los elementos de la naturaleza en una nueva estructura heredera de la técnica pictórica, ya no para atrapar el flujo de la realidad tal y como se presenta ante él, sino para reflejar la realidad a partir de la revelación aparente de sus características esenciales. Estas consideraciones demuestran que el dominio de la técnica resulta imprescindible para posibilitar un acercamiento del espectador a la intensidad emocional expresada por el rostro del actor. Por su parte, Elsaesser sugiere que la transmisión o comunicación de sentimientos es una de las preocupaciones primordiales en la obra de Bergman, puesto que 
"utiliza procesos estéticos específicos del cine (la manipulación del espacio por ejemplo) no para crear efectos intelectuales, sino para transmitir estados psico-fisiológicos [...] que son una parte integral de sus temas morales" (1971, p. 8).

Erland Josephson, uno de los actores fetiche del director sueco, dice que "Ingmar siempre ha soñado con una película experimental con una sola actriz -no actor-, y encuadrando básicamente su rostro, concentrar en él todo el drama, sin cortes ni edición" (Llano, 2005, p. 81). Estas palabras revelan el deseo frustrado de realizar un retrato cuya imagen sea la de su duración, capaz de conseguir "la momificación del cambio" (Bazin, 1990, p. 29) de manera ininterrumpida, y coincidiendo además con Aumont en la idea de que "filmar un rostro es plantearse todos los problemas del filme, todos sus problemas estéticos, luego todos sus problemas éticos" (1998, p. 88). Sin embargo, debe entenderse la utilización de los primeros planos en la obra de Ingmar Bergman como un medio técnico para profundizar en el interior del personaje, es decir, como tentativa por alcanzar la psique del hombre mediante una proximidad material con el rostro, y no de una simple experimentación de la técnica cinematográfica, o, en el caso de la mirada a cámara del personaje, de un juego con la reacción del público (Steene, 1970, p. 27). La actriz Liv Ullmann habla sobre el problema de ajustar su técnica interpretativa del teatro al cine de Bergman: "Ahora me siento más cómoda en el cine. Con los primeros planos he sido capaz de encontrar una técnica íntima que funciona muy bien para mí: el verdadero pensamiento se mostrará en tus ojos" (Wexman \& Ullmann, 1980, p. 76). Si el rostro condensa todo su cine, no es sólo como expresión material de lo inmaterial, sino también como un catalizador del mundo que lo rodea. El rostro "como articulación crucial, entonces, de exterioridad e interioridad", en palabras de José Luis Brea (1991, p. 107), por el cual circula el sentido de lo narrado vía primer plano.

En El hombre visible (1924), el primer libro de Béla Balázs, ya aparece formulada la idea de equivalencias entre distancias físicas y emocionales en relación al personaje/actor y al espectador/cámara que, en conjunción con 
una persistencia en el tiempo del plano, haría realidad la revelación del alma. El escritor Pere Gimferrer, al referirse a Persona (1966) de Ingmar Bergman, parece entablar una relación directa entre el espacio y el tiempo dirigido al rostro y su capacidad de abstracción en el medio.

La simple presencia física de los actores, dirigidos férreamente en planos que, por su cercanía y larga duración, tienden a anular la distancia entre actor y personaje, establecerá con el espectador una comunicación tan intensa y de una naturaleza tan peculiar que se podrá producir una efectiva vaporización, una especie de escamoteo, del entorno en el que los actores evolucionan (2000, p. 75).

Aquí es posible observar cierta semejanza con el planteamiento deleuziano que explica cómo el primer plano de un rostro no es un objeto parcial separado del conjunto al que pertenece, sino que, de acuerdo con Balázs, eleva al rostro al estado de Entidad mediante la abstracción de las coordenadas espacio-temporales. Deleuze recupera las palabras de El film. Evolución y esencia de un arte nuevo (1945), último ensayo sobre teoría fílmica de Balázs, para aclarar el origen de sus ideas en torno al primer plano del rostro como técnica particular del cine capaz de descubrir la realidad.

La expresión de un rostro aislado es un todo inteligible por sí mismo [...]. Porque la expresión de un rostro y la significación de esta expresión no tienen ninguna relación o enlace con el espacio. Frente a un rostro aislado, no percibimos el espacio. [...] Ante nosotros se abre una dimensión de otro orden (1984, p. 142).

La entidad es el afecto, lo expresado por el rostro y no el rostro mismo. En otras palabras, Deleuze afirma que con el primer plano surge de la cualidad del rostro, que es inherente a éste, y conjuntamente forman un todo llamado icono. Por lo tanto, de un primer plano de un rostro sucede su afecto en lo que Deleuze denomina “plano-afección”. En este momento ocurre una separación entre el rostro y su portador, una ruptura en el anclaje del rostro con sus referentes que lo aísla despojándolo de su individuación. El primer plano de un rostro es el rostro mismo, pero se trata de un rostro anulado, sin referentes, con sus funciones en suspenso. Finalmente, Deleuze explica el 
resultado del estudio fisonómico que Bergman convierte en retrato filmado del hombre:

Bergman llevó hasta su extremo el nihilismo del rostro, es decir, su relación en el miedo con el vacío o con la ausencia, el miedo del rostro frente a su nada. En toda una parte de su obra Bergman alcanza el límite supremo de la imagen-afección, quemando el icono, consumiendo y extinguiendo el rostro (1984, pp. 143-148).

Ingmar Bergman lanza una mirada descreída hacia el interior del ser humano que se pierde en el vacío, donde la única verdad es la falta de verdad y la incertidumbre se desvela en una solución inadvertida que desmiente una constancia tras la apariencia cambiante.

\section{Conclusiones}

La transición se convierte en motivo de la existencia indefinida entre el tiempo y el espacio en la obra de Ingmar Bergman. El devenir en perpetua fuga desliza su sentido en la materialidad de la representación y convierte al rostro en un espacio de intertextulaidad que, más allá de ser una simple unidad de montaje, es un fin en sí mismo. De acuerdo con esto, la técnica cinematográfica del primer plano interviene para exaltar la ambigüedad del rostro mediante la obturación de su espacio externo, pues aislar el fragmento del cuerpo concreta los imprecisos detalles de su composición mientras intenta rastrear las huellas de lo anómalo que hay en él. El observador descifra la imagen del rostro a partir de sus cualidades fisonómicas, pero a falta de un sentido, reconstruye con una mirada melancólica -teñida de “conciencia de pasado" (Brea, 1991, p. 43)- la identidad del modelo de manera alegórica. Es decir, el espectador crea un imaginario presente sobre la huella que ha dejado el pasado, y esta es la misma esencia temporal del cine, pues como afirma Morin, "si pasado y presente se confunden en el cine es porque la presencia de la imagen tiene ya, implícitamente, el carácter emotivo del pasado" (2001, p. 59-60). Bergman, por tanto, piensa el rostro como pantalla cinematográfica cuya existencia es la duración de una 
proyección, ya que tanto el hombre como el cine son puro movimiento, apariencia de la variación en su fluir temporal abocado a la finitud. No obstante, el cine se convierte para Bergman en la única herramienta capaz de alcanzar al hombre, porque ambos parecen estar fabricados con el mismo material onírico.

Su búsqueda pretende hallar algo en el rostro que escapa a su construcción alegórica, algo que no pertenece al ámbito subjetivo de su receptor y se oculta entre el tejido selvático de las facciones. Sin embargo, las respuestas que obtiene, o más bien, la falta de respuestas, conducen a Bergman a un convencimiento materialista del sujeto en constante transformación y movimiento; incognoscible porque no hay nada que conocer. Un rostro sin rostro es el resultado del retrato del hombre bergmaniano; una esencia evaporada tras las pupilas enmarcadas en una fisonomía que expresa lo que no existe. En su cine parece haber un deseo de aniquilación del individuo que imposibilita su descubrimiento, pues lo visible es la única demostración de una existencia a través de los sentidos, y más allá de la imagen del rostro, sólo la imaginación puede tomar las riendas de lo concebible. "El vacío es como un espejo puesto delante de mi rostro" (19'23”), afirma Antonius Block (Max von Sydow), el caballero de El séptimo sello (Det sjunde inseglet, 1957) que se confiesa, sin saberlo, ante la muerte. Y es que la faz no es más que una efigie compuesta por fascículos, un conjunto de fibras musculares y nerviosas exteriorizadas en forma de muecas y visajes cuyo lenguaje gestual pertenece al ámbito de lo alegórico, pues en la heterogénea vibración de la carne se enuncia el sentido oculto necesario para cerrar un círculo comunicativo sin respuesta, un grito frente al abismo que devuelve un eco imaginado. Lejos de encontrarse perdido, Bergman vaga voluntariamente por un desierto en el que sólo acierta a ver espejismos, haces de luz imaginados sobre una pantalla vacía que alimenta la quimera de su verdadera existencia más allá de imagen.

\section{Referencias bibliográficas}

Alpert, H. (1961). Style is the Director. Saturday Review of Literature, pp. 39-41. 
Aumont, J. (1988). El rostro en el cine. Barcelona: Paidós.

Barthes, R. (1989). La cámara lúcida. Nota sobre la fotografía. Barcelona: Paidós.

Baudelaire, C. (1995). El pintor de la vida moderna. Bogotá: El Áncora.

Bazin, A. (1990). ¿Qué es el cine? Madrid: Rialp.

Benjamin, W. (2007). Sobre la fotografía. Valencia: Pre-textos.

Bergman, I. (1977). Cara a cara. Barcelona: Aymá.

Bergman, I. (1992). Imágenes. Barcelona: Tusquets.

Bergman, I. (1998). Las mejores intenciones. Barcelona: Tusquets.

Bergman, I. (1988). Linterna mágica. Barcelona: Tusquets.

Bergman, I., Burke, P. E., Swahn, L. \& Munk, E. (1966). Each Film is My Last. The Tulane Drama Review, 11 (1), pp. 94-101.

Björkman, S., Manns, T. \& Sima, J. (1973). Conversaciones con Ingmar Bergman. Barcelona: Anagrama.

Brea, J. L. (1991). Nuevas estrategias alegóricas. Madrid: Tecnos.

Deleuze, G. (1984). La imagen-movimiento. Estudios sobre cine I. Barcelona: Paidós.

Del Río, V. (2008). Fotografía objeto. La superación de la estética como documento. Salamanca: Ediciones Universidad de Salamanca.

Duchamp, M. (1975). The Creative Act. En M. Sanouillet \& E. Peterson (Ed.). The essential writtings of Marcel Duchamp (pp. 138-140). London: Thames and Hudson.

Elsaesser, T. (1971). Reflection and Reality: European art cinema. Monogram, 2, pp. 2-9.

Gimferrer, P. (2000). Cine y literatura. Barcelona: Seix Barral.

Gombrich, E. H. (1966). La máscara y la cara: La percepción del parecido fisonómico en la vida y en el arte. En M. Mandelbaum (Ed.). Arte, percepción y realidad (pp. 15-67). Barcelona: Paidós.

Gubern, R. (2004). Patologías de la imagen. Barcelona: Anagrama.

Hume, D. (1988). Tratado de la naturaleza humana. Libro I, parte IV, sección VI. Madrid: Tecnos.

Kracauer, S. (1996). Teoría del cine. La redención de la realidad física. Barcelona: Paidós.

Livingston, P. (2009). Cinema, Philosophy, Bergman. On Film as Philosophy. Nueva York: Oxford University Press.

Llano, R. (2005). Erland Josephson: Entre Bergman y Tarkovsky, por un camino con charcos. Revista Teatral de la Asociación de directores de escena de España (108), pp. 74-86. 
Morin, E. (2001). El cine o el hombre imaginario. Barcelona: Paidós.

Nietzsche, F. (2006). Segunda consideración intempestiva. Buenos Aires: Libros del Zorzal.

Nykvist, S. (1998). Culto a la luz: Conversaciones con Bengt Forslund sobre el cine y su gente. Madrid: Del Imán.

Proust, M. (2007). El mundo de Guermantes. En busca del tiempo perdido, vol. III. Madrid: Alianza.

Rilke, R. M. (1958). Los cuadernos de Malte Laurids Brigge. Buenos Aires: Losada.

Shakespeare, W. (1825). Hamlet: tragedia. Obras dramáticas y líricas de D. Leandro Fernández de Moratín, vol. III. París: Augusto Bobée, pp. 1280.

Steene, B. (1970). Images and Words in Ingmar Bergman's Films. Cinema Journal, 10 (1), pp. 23-33.

Wright Wexman, V. \& Ullmann, L. (1980). An Interview with Liv Ullmann. Cinema Journal, 20 (1), pp. 68-78.

Cómo citar: Vázquez Couto, D. (2016). "Apariencias de la variación: Fisonomía y alegoría en el retrato cinematográfico de Ingmar Bergman”. Fotocinema. Revista científica de cine y fotografía, $\mathrm{n}^{\mathrm{o}} 12$, pp. 131-154. Disponible: http://www.revistafotocinema.com/ 